\title{
SMARTPHONE-BASED VOLUNTEERED GEOGRAPHIC INFORMATION (VGI) FOR SLUM MAPPING IN POKHARA CITY OF NEPAL
}

\author{
K. Ranabhat*, D. R. Paudyal \\ Faculty of Health, Engineering and Sciences, University of Southern Queensland, Toowoomba, Queensland - \\ kuberbhat@gmail.com,devraj.paudyal@usq.edu.au
}

Commission V, WG V/7 \& Commission IV, WG IV/6

KEY WORDS: Informal Settlements, Volunteered Geographic Information (VGI), Crowdsourcing, Smartphones, Slum Mapping

\begin{abstract}
:
Informal settlements in urban areas are increasing rapidly throughout the world and regularisation of these settlements is being one of the challenging issues. Various study results have shown that conventional cadastral based information system approach and government managed institutional arrangements do not appropriately address land management issues of slum settlements. The aim of this study is to explore application of smartphone based Volunteered Geographic Information (VGI) and open spatial tools for slum mapping in developing countries such as in Nepal. A case of Pokhara Metropolitan city has been considered to explore the potential of utilization of smartphone based VGI and open spatial tools for slum mapping. Attribute and spatial data were collected using Smartphones and community-driven approach. Spatial and attribute data collected from 229 respondents of household's surveys are integrated, analysed and interpreted and presented in this paper. Open Street Map (OSM) platforms and QGIS open source software have been used for slum mapping. These maps could play an important role in providing spatial information to the local government and planning authority in Nepal. This research paper concludes that smartphone based VGI and open portals such OSM have great potential to contribute to develop slum database and in providing information to plan various strategies, which aims at understanding, regularisation and upgrading slums.
\end{abstract}

\section{INTRODUCTION}

\subsection{Background}

For most of the developing countries, the regularisation and upgrading of informal settlements in urban cities have been a big problem for the government and to the local residence residing near such settlements. Nearly, 1 billion people reside in slums worldwide and it is predicted to increase up to 2 billion by 2030 (UN-HABITAT, 2013). Informal settlements are residential areas where 1) residents have no land tenure security, 2) lacks the formal basic services and city infrastructure such as supply of clean drinking water, health facilities, lack of electricity etc., 3) located in environmentally and geographically high risk zone and also housing may not fulfil building guidelines (UN-HABITAT, 2015).

In context of Nepal, informal settlement (Sukumbasi Basti) are relatively new and have only 20 to 30 years of history in major cities of Nepal (Paudyal and McDougall 2010). Nepal Government made several unsuccessful attempts to protect government or public land encroachment by informal settlements through forced eviction, while in the recent phase government has failed to address these issues through resettlement project in the surrounding of the urban cities (Brooks 2016). There are very few efforts from the government of Nepal to regularise slum settlements. After the restoration of democracy in 1990, a new high-level political commission Sukumbasi Samashya Samadhan Aayog (SSSA) was formed in 1995 to work for landless people and informal settlements in Nepal. Later, this commission received 263,738 applications demanding for property rights and land ownership certificates. SSSA verified the applications and identified 54,170 families as a real informal settlements (Sukumbasi). To regularise these settlements, the commission had distributed land ownership certificates to 1278 families, while 10278 families received temporary land entitlement paper (Jagannath 2008). For addressing the issues related with informal settlement, Nepal government in its policy level has been working for legalisation, resettlement and regularisation and upgrading of informal settlement (Paudyal and McDougall 2010).

\subsection{Role of VGI Managing Informal Settlements}

The use of various GIS technology for urban planning has significantly been increased (Martinez 2009). As VGI uses bottom-up approach of spatial data collection, it helps the planner to understand and improve the quality of slum settlements (Hachmann, Arsanjani and Vaz 2018). VGI could play a vital role to collect enough information and can be useful for developing countries which has incomplete cadastral coverage and insufficient land records. An option to cadastral system can be developed using VGI for identification of land and land use (McLaren 2011).

\subsection{Previous Research on Regularisation of Informal Settlements}

Shrestha (2013) in his research "Squatter settlement in the Kathmandu Valley, Nepal" found that the informal settlements are due to a poor LA system, poor governance, low socioeconomic growth and incapability to manage housing needs. Lack of public investment, lack of financing option and social exclusion are the major problems faced by settlers due to lack of land rights and land tenure.

Hachmann, Arsanjani \& Vaz (2018) has used spatial data for slum upgrading. During their research they investigated the

\footnotetext{
* Corresponding author
} 
implementation of Volunteered Geographic Information (VGI) and citizen science (CS) for collection of spatial information on informal settlements. They concluded that VGI and Citizen Science present powerful approaches to collect data on a larger scale and have potential to replace or complement Public Participation GIS (PPGIS) in slum upgrading practices. They urged that VGI could play an important role in providing more accurate and up-to-date spatial information through public participation (bottom-up approach) for urban planner which could be great help for understanding, regularisation and upgrading the realities of slum settlements.

Magigi and Majani (2006) in their research study found that involving slum settlers in decision making and educating them about local issues is an important aspect for regularisation of slum settlement.

\subsection{Use of Smartphone and Open Data Kit}

A case study of the Scottish crofting community employed Smartphone-based VGI approach for cadastral purpose ((Duchateau \& Mackaness 2017). CroftCappture, a locationbased android application was tested by crofters and recorded boundary points, photographs and notes. Results have shown that such applications help to clarify boundary complexities from collected photographs and notes and help to record stories about crofts (agricultural units of under 50 hectares).

According to McLaren (2013) smartphone based VGI for land administration is in use and only little research has been done about its implications in recording land information for cadastral purposes. Further, McLaren et al. (2018) have developed a practical guide for implementing new technologies for land administration, including crowdsourced data and drone technology for data capture. This guide also offers a comprehensive overview of emerging trends in land administration through various case studies (Lengoiboni,etal 2019). Three popular mobile applications in land administration are USAID's Mobile application for security of land tenure and Food, Agriculture Organisation (FAO's) open tenure and Open Data Kit

USAID has launched the Mobile Applications to Secure Tenure (MAST) initiative which uses smart phones/tablets and a participatory approach to efficiently, transparently, and affordably map and document land and resource rights (USAID, 2019).

Open Tenure was developed by FAO with financial support from the UK Department for International Development (DFID). It uses handheld tablets, and a community server to map and collect data on land tenure claims. It supports a crowd sourcing approach to the collection of tenure related details by communities. The data can then be viewed and moderated, and important documents and photos can be stored electronically (FAO, 2019). Open Data Kit is an android application which was developed at the University of Washington to use a smartphone as a data collection device. It is being used around the world to collect information in a cheaper way in places with insufficient infrastructure. Children from Rishi Aurobindo Colony, Kolkata, India have been mapping their own slum community using smartphone and Open Data Kit application with the funding of UNICEF (McLaren 2013)
This research paper has explored smartphone-based unconventional approaches such as VGI and Crowdsourcing for slum settlements mapping in Nepal. On the basis of collected spatial and attribute data using smartphone as a tool, it was explored that smartphone based VGI approach could contribute for regularisation of slum (Sukumbashi Basti) in developing countries such as in Nepal.

\section{METHODOLOGY}

The case study area is located in Pokhara Metropolitan City which is situated in Gandaki Province of Nepal. Pokhara is located $200 \mathrm{~km}$ West of capital city Kathmandu and is the largest city of Nepal in terms of area. There are large number of informal settlements in Pokhara, among which three settlements were taken as representative cases (Figure 1).

- $\quad$ Shanti Tole Informal Settlement (Ward 01)

- Pragati Nagar and Pragati Tole Informal Settlement (Ward 07)

- Simaltuda, Hanuman and Namuna Tole Informal Settlement (Ward 17)

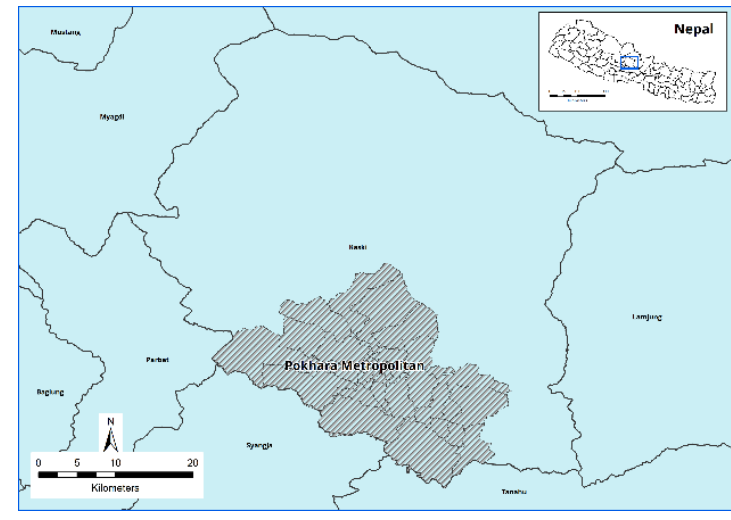

Figure 1. Location Map of Nepal, Kaski District and Pokhara Metropolitan City

As illustrated in Figure 2, the research methodology focuses on spatial and attribute data collection using smartphone as a major data collection tool. The Questionnaire were prepared and field survey consist of house hold survey and slum mapping using smart phone device and open street map.

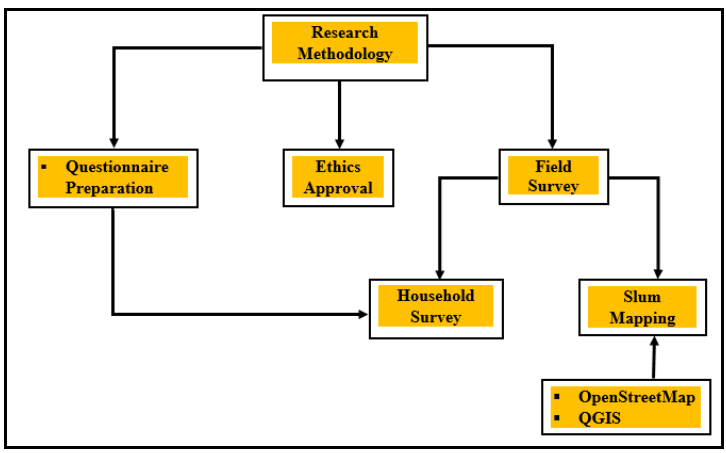

Figure 2. Methodology Workflow

\subsection{Questionnaire Preparation}

A questionnaire was designed to collect relevant attribute data 
from slum communities which consists of 30 questions related to personal information, socio-economic situation of slum settlers, basic infrastructure status, slum settler's views on upgrading settlements as well as on property rights. First of all, all the questions were manually entered into the KoBoToolbox which is an open source survey tool for data collection. One of the advanatages of using this tool is that it can be used in both online and offline mode.

\subsection{Ethics Approval}

Before undertaking the field survey, the ethics application was submitted to the USQ Human Research Ethics Committee through USQ Research Information Management System (RIMS) and ethics approval was obtained.

There was voluntary participation in the survey and the participants were informed and assured through a statement that participants' confidentiality would be maintained during data collection and presenting the research report. If any of the participant would be interested to see the research results, the summary of the results would be made available upon request. NextCloud was used for research data transfer and USQ's Research Data Bank (ReDBank) was used to store, share and synchronise the research data during this research projects.

\subsection{Field Survey}

Field survey during this research was carried out using smartphones, which had improved the efficiency of work and minimised the risk of losing data. In addition to this, using these technologies also reduced the time for re-entering data collected in field and helped in post-processing of data as we directly obtained data in a digital tabular form. The main mobile applications used during the field survey were OSM tracker and KoBoCollect which are freely available on google play store and doesn't require internet connection to operate. The locally trained/grassroots surveyors were involved during the data collection. Those grassroots surveyors were young adults from the slum settlements, trusted by the communities and educated and guided by professionals. A brief introduction about the aim of the research was provided to them and were made familiar with mobile phone application for data collection.

For this research study, Smartphone with OSM Tracker app had been used to collect the track of spatial data along with other attribute information such as house number, name of locality etc. from field and those data were used for further processing (to create a map). We had recorded various data using the tools available such as taking photos, recording voice, and taking notes which were available within the application feature. After the collection of spatial data, it was then uploaded into the OSM website (www.osm.org) using the JOSM editor application. In JOSM editor application, we had edited the collected spatial data using Bink and Maxar satellite imagery as a background layer. Finally, the information was uploaded into the site and it was saved.

Similarly,, attribute data related to slum settlements were collected through household survey. Out of 33 wards in Pokhara Metropolitan City, three different wards were selected as representative case. The criteria for selecting these cases were location of slum settlement, size of slum settlement, and age of settlement. Informal settlement in ward 01 is located in the bank of Seti River (flooding/risk area), ward 07 is located on the heart of Pokhara city and and ward 17 is the largest informal settlement in Pokhara Metropolitan with 1080 households.

These three informal settlements were surveyed and the attribute data were collected via household survey using another mobile application named as KoBoCollect (v1.23.3k). KoBoCollect is a mobile application which allows us to perform survey through the questions designed in KoBoToolbox, when login credentials of KoBoToolbox are given to KoBoCollect. KoBoToolbox and KoBoCollect are interlinked applications i.e. questionnaire are created and hosted through KoBoToolbox and accessed through KoBoCollect mobile application and if questionnaire is updated in one KoBoToolbox, updated version of it can easily be accessed through KoBoCollect. The questionnaire was designed such that the spatial location (i.e. latitude and longitude) of all surveyed household was captured at the starting of the survey otherwise the form could not be proceed forward. When the household survey was completed, forms were marked and finalised on the mobile device. The finalised forms were submitted from KoBoCollect, those data were updated in KoBoToolbox website and could be viualised as illustrated in Figure 3. Then, the collected data were extracted in MS-Excel format from the KoBoToolbox application for further analysis.

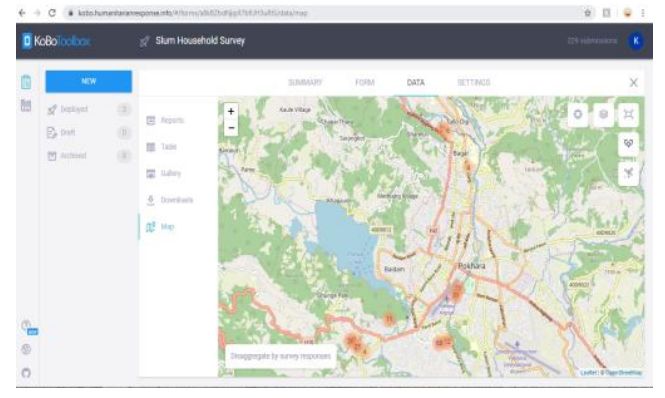

Figure 3. KoBoToolbox used for Household Survey

\section{RESULTS}

\subsection{Land Title and Household Survey}

From the household survey, it was found that $96.96 \%$ (223 out of 229) of participants were occupying government land from many years and they do not have any kind of legal documents regarding the land ownership. While few (6 out of 229) were found to have restricted ownership of the occupied land, which was provided by High Level Commission formed by government of Nepal. In restricted ownership, settlers do not have full ownership right till the allocated time duration (it was found to be around 15 to 25 years). From Figure 4, it can be found that $110(48.03 \%)$ participants were living in their current location from more than 15 years (in many cases more than 25 years). While $13.1 \%$ of participants were found to be residing in these settlements from less than five years. During the survey, they were asked about their property in other district of Nepal. It was interesting to see that 45 out of 229 participants $(19.65 \%)$ responded that they do have land ownership in other part of the country. In addition to this, they 
added that they are residing as a slum as they cannot afford to buy a property in their current location and are here because of natural calamities and lack of opportunities for earning in their previous location.

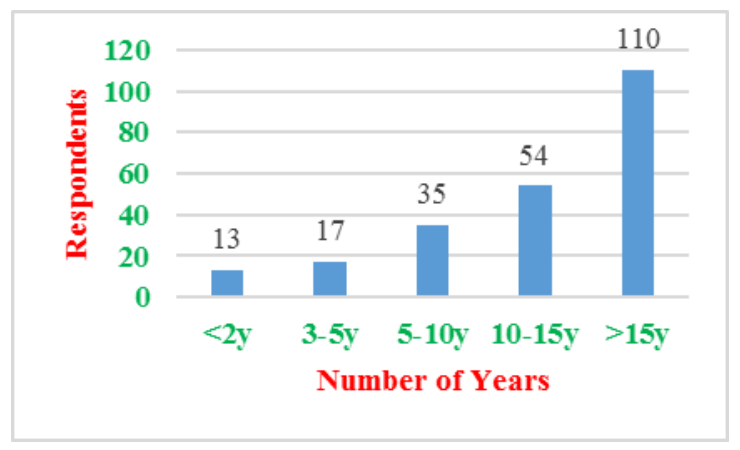

Figure 4. Duration of stay in the settlements (from sampled households)

During the survey, participants were asked about the procedure for land transaction in their current (informal) settlements. Interestingly, such occupied government lands are being bought and sold in presence of slum community leaders and members, with the mutually agreed locally signed deeds out of formal registry (signed and agreed by buyer and seller). From the sampled household survey of 229 respondents, $65.5 \%$ of participants responded that the land transaction has been done since these settlements were started. While $34.5 \%$ of participants responded that land transaction is not possible in their settlements. According to them, land transaction has been done with paperwork in presence of local slum community leaders, members and elders, signed and agreed by buyer and seller. But the buyer has to pay some fees to the local slum community before doing the transaction.

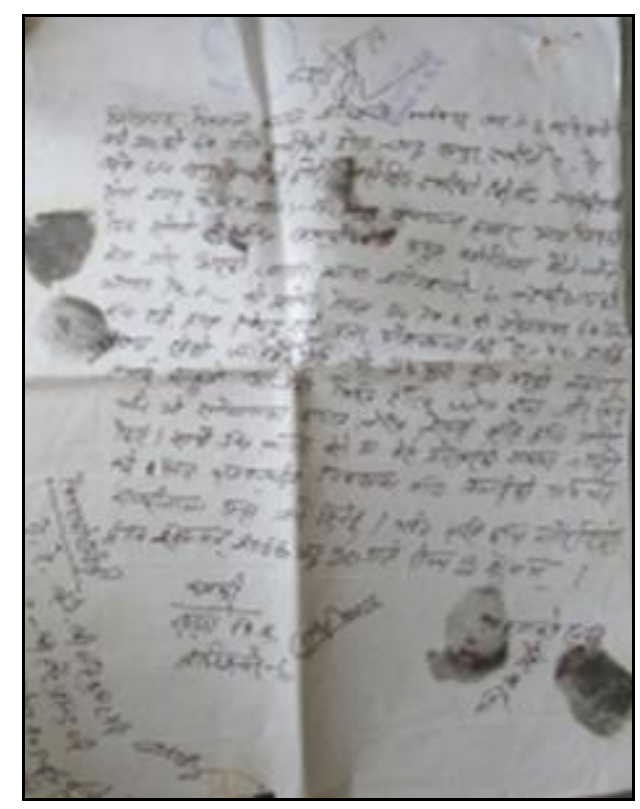

Figure 5. Agreement for land transaction

From the survey, it was found that informal settlements have their own cadastral map along with the record of area of land plot occupied by each family, which was prepared by Sukumbasi Samasya Samadhan Aayog in 2009 but have not been legally registered in the official cadastre of government of Nepal till date.

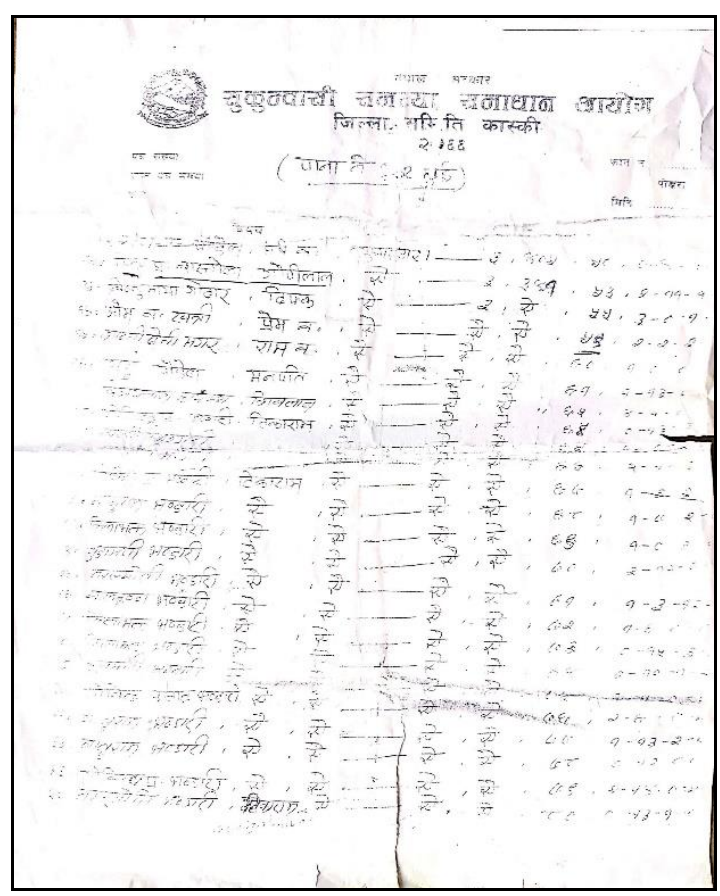

Figure 6. Record of area of land plots

During questionnaire survey, majority of people (96\%, 220 out of 229) agreed that the condition of health service in their community is poor. They also added that high medical cost discourage them from visiting doctors. As an alternative to visit medical professionals, they prefered to go to quack doctor and traditional healers. From the survey, it was found that condition of water services in informal settlement is poor (as per the response of $89.86 \%$ participants).

Regarding shelter and settlement conditions, Sand Cement Block (wall material) and Tin (roof material) are used as primary building materials, which is easily available and inexpensive. From the survey, it was found that $83.84 \%$ (192) and $93.89 \%$ (2015) of participants had used Sand Cement Block and Tin to construct their houses respectively. Most of the houses in slum settlements were found to be poor, they are living in the same house since one-two decades. From the survey, it was found that $47.6 \%$ of houses were constructed before 2004. As per the questionnaire survey, 74 out of 229 responded that there is a risk of natural hazard. Flood, landslide and sinkhole formation are the major risk in these settlements.

During the survey, they were asked a question about relocation and it was interesting to see their response. As per their response, $145(63.32 \%)$ were happy to relocate whereas 84 $(36.68 \%)$ did not want to relocate from their current location. The key things they would be looking for relocated area are:

- Land ownership certificate along with house in the vicinity of city;

- Better employment opportunities;

- Availability of all basic facilities: Hospital/Health Post, School, Water, Road, Drainage, Sanitation etc. 
From the survey, it is found that the participants (100\%) are not aware of unconventional approaches such as VGI and Crowdsourcing. And they have never used smartphones for collecting data to prepare maps.

\subsection{Slum Mapping}

Slums are the most untraceable and un-surveyed parts of developing cities. Informal settlements mostly spotted as a blank spots: neglected and unmapped areas on most of the cadastral maps and planning documents. The edited and updated geographical data was published on OSM for slum traceability in three wards (Ward 01, 07, and 17) of Pokhara Metropolitan City as shown in Figures 8, 9 and 10. This has made it possible to record and visualise (number of houses count, road network status, tracing other infrastructures) of slums in these three wards of Pokhara Metropolitan City. Because of limitations of time and finance, attribute data of 229 participants were collected and appropriate data were successfully uploaded and added using OSM. And those data could be accessed and uploaded through the OSM site.

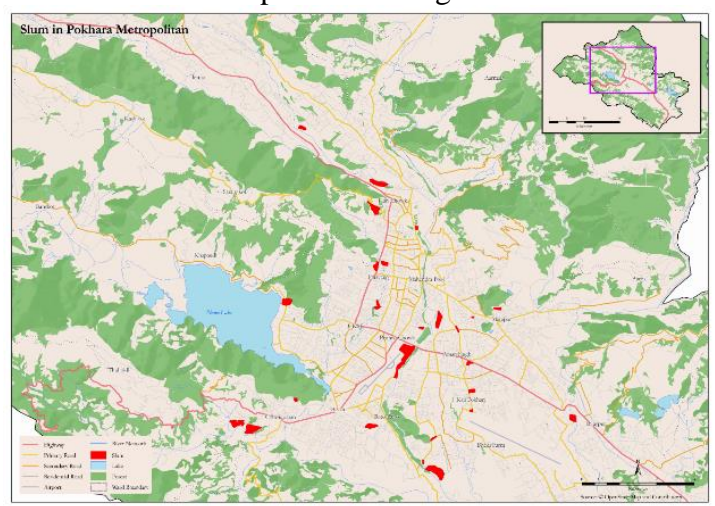

Figure 7. Informal Settlements in Pokhara Metropolitan City

Figure 7, illustrates the location of different informal settlements in Pokhara Metropolitan city. Red colour polygon represents the informal settlements in various parts of Pokhara city.

In Figure 8, 9 and 10, red colour housing data (polygon) indicates the houses surveyed during field visit. Out of 229 household surveyed, 30 were from ward-01, 52 from ward-07 and 147 from ward-17, all are shown by red colour polygon on Figure 8, 9 and 10 .

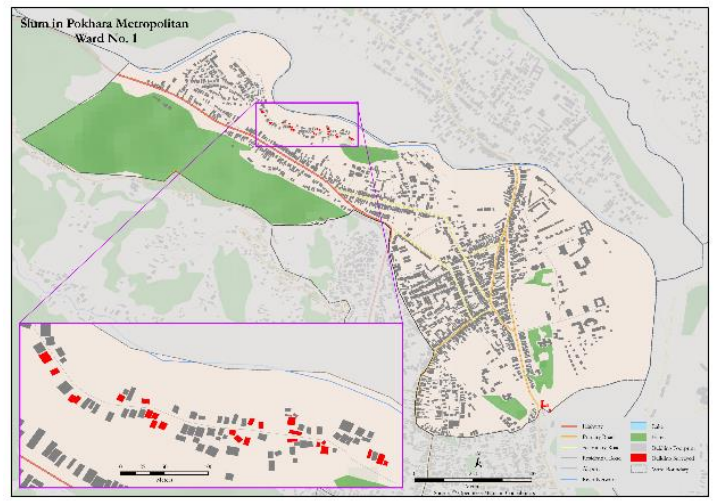

Figure 8. Slum in Pokhara Metropolitan Ward No. 01

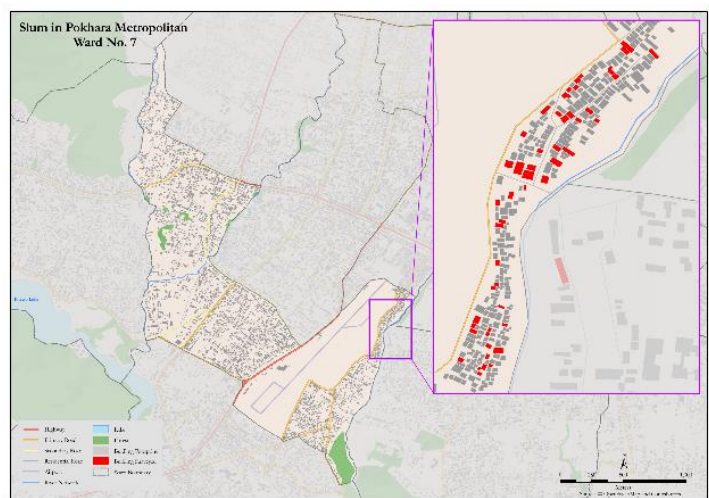

Figure 9. Slum in Pokhara Metropolitan Ward No. 7

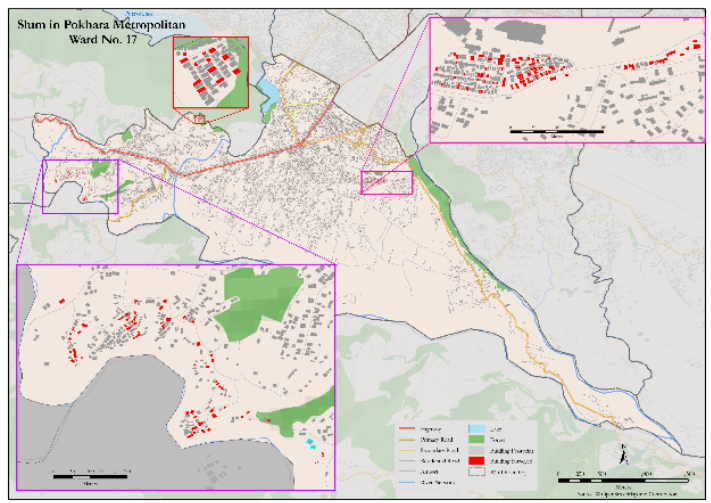

Figure 10. Slum in Pokhara Metropolitan Ward No. 17

\subsubsection{Before and After OSM Mapping}

Figure 11 illustrates the comparison of study area of ward 07 before and after this research. Before this research, no housing data and other infrastructure of slum settlements were recorded on OSM. But after this research, every house and other infrastructures such as roads, temples, schools, community buildings were mapped. And attribute data collected from 229 sampled household were also entered and recorded on OSM.

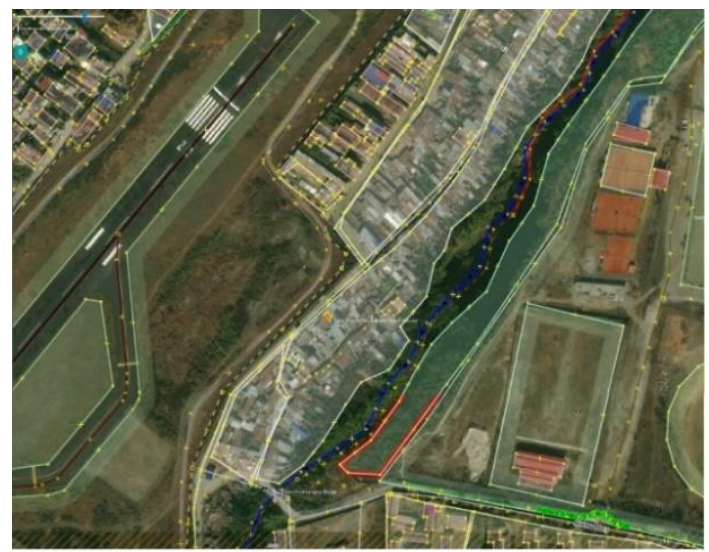

Before this research 


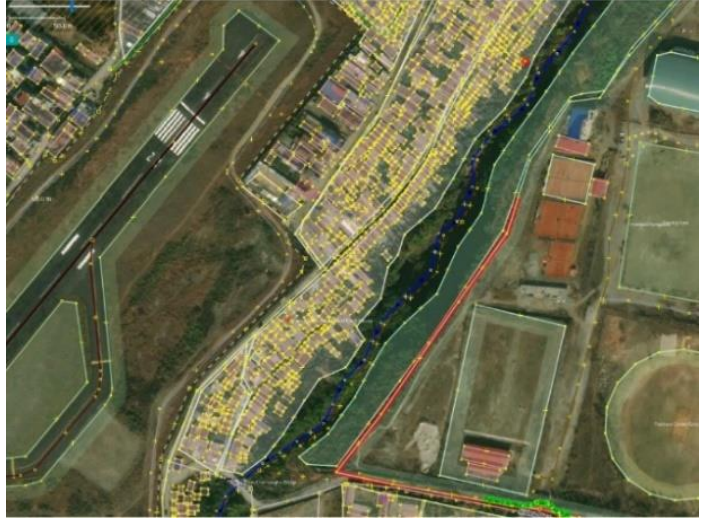

After this research

Figure 11. Study Area (Ward 07)

\subsubsection{Overlay of Official Cadastral Map with Satellite Imagery}

The main purpose to overlay cadastral map with freely available satellite imagery was to illustrate what is the status in the official record and what it looks like in the reality. As illustrated in Figure 12, yellow block indicates land parcels (ward 07) which is recorded in the official cadastral records of Government of Nepal (formal settlement). Whereas, the red block represents slum/informal settlement which is a vacant governmental land as per the official record (cadastral map) of Government of Nepal. However, there is a highly populated and dense settlements in field which has not been recorded in any official documents/maps. It was found that Informal settlement occupying the government, public and private lands, are neither legally recognised nor registered in official cadastre.

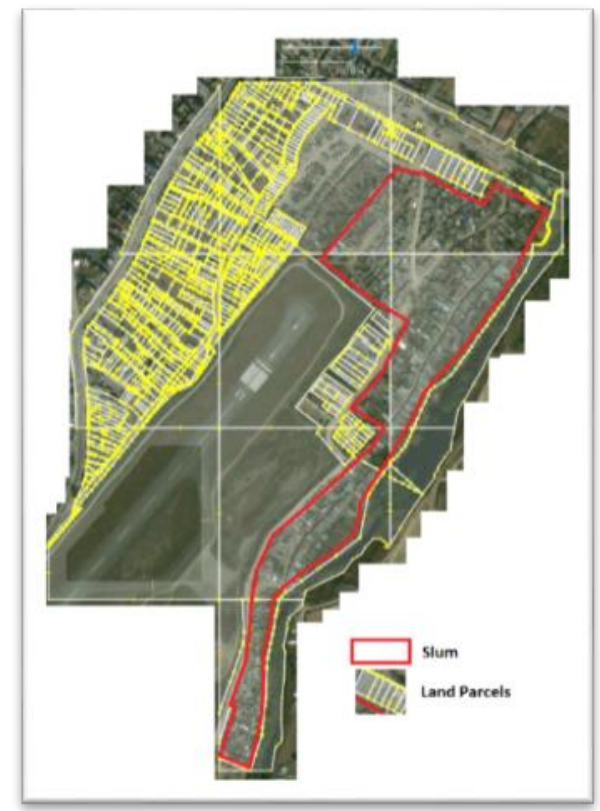

Figure 12. Overlay of Cadastral Map with Satellite Imagery (ward 07 along with some part of ward 09)

\section{DISCUSSION AND CONCLUSION}

Smartphone based VGI have been used in various part of the world for land administration, cadastral purpose and mapping. Smartphones can be effectively used for data collection and mapping in areas which lacks data and information such as informal settlement, as these technology are cheap and quick to use. The major problem in using smartphone for data collection and mapping is low accuracy. And in context to this study, locally trained/grassroots surveyors were involved during data collection. Those grassroots surveyors were young adults from the slum settlements, trusted by the communities and educated and guided by professionals. A short brief was given to them about the aim of the study and were made familiar with mobile phone application for data collection.

In this paper, application of smartphone based VGI and open spatial tools were explored. Smartphone applications were used to collect spatial and attribute data. Likewise, the detailed study to identify the current status of the informal settlements was achieved through household survey. Informal settlements mapping was done using Open Street Map (open source mapping tool) and QGIS (open source software) using the collected spatial and attribute data.

\section{REFERENCES}

Adhikari, J., 2008. Land reform in Nepal. Problems and Prospects. ACTIONAID-Nepal, Kathmandu.

Brooks, R., 2016. Relocation, Resistance and Resilience: Squatter Community Responses to Government Intervention for Urban Development in Kathmandu.

Duchateau, R. and Mackaness, W.A., 2017. Smartphone-based volunteered geographic information for land registration: the case of the Scottish crofting community. GISRUK 2017 Proceedings, p.91.

FAO (2019): Open Tenure Crowd Sourcing Software, http://www.fao.org/fileadmin/user_upload/nr/land_tenure/OPE N_TENURE.pdf Accessed 18/11/2019

Hachmann, S., Arsanjani, J.J. and Vaz, E., 2018. Spatial Data for Slum Upgrading: Volunteered Geographic Information and the role of Citizen Science. Habitat International, 72, pp.18-26.

Lengoiboni, M, Richter, C, Zevenbergen,J (2019): Crosscutting challenges to innovation in land tenure documentation, Land Use Policy, Volume 85, 2019,Pages 21-32,ISSN 02648377, https://doi.org/10.1016/j.landusepol.2019.03.023.

Magigi, W. and Majani, B.B.K., 2006. Community involvement in land regularisation for informal settlements in Tanzania: A strategy for enhancing security of tenure in residential neighborhoods. Habitat international, 30(4), pp.1066-1081.

Martínez, J., 2009. The use of GIS and indicators to monitor intra-urban inequalities. A case study in Rosario, Argentina. Habitat International, 33(4), pp.387-396. 
McLaren, R., 2011. Crowdsourcing support of land administration-A partnership approach. Article of Month.

McLaren, R., 2013. Technology to promote transparency around land acquisitions. Evidence on Demand, London.

McLaren R, Fairlie,K D'Souza, G and Kathrine , K, 2018. World Bank Guide - New Technology and Emerging Trends: The State of Play for Land Administration, Conference Proceedings, Annual Land Bank Conference on Land and Poverty, 19-23 March 2018, The World Bank, Washington, D.C

Paudyal, D.R. and McDougall, K., 2010. Spatial Data Infrastructure for Pro-poor Land Management. In Proceedings of the 24th International Federation of Surveyors International Congress (FIG 2010) (pp. 1-14). International Federation of Surveyors (FIG).

Shrestha, B.K., 2013, Squatter settlements in the Kathmandu valley: Looking through the prism of land rights and tenure security. In Urban Forum (Vol. 24, No. 1, pp. 119-135). Springer Netherlands.

USAID (2019): Changes in Land Security and Availability https://www.land-links.org/2019/06/understanding-landscapesusing-spatial-data/ Accessed 18/11/2019

UN Habitat, 2015, April. Habitat III Issue Papers, 22-Informal Settlements. In United Nations Conference on Housing and Sustainable Urban Development (Vol. 2015).

United Nations Human Settlements Programme, 2013. The challenge of slums: global report on human settlements, 2013. UN-HABITAT. 